\title{
Micro-CT supporting structural analysis and modelling of ropes made of natural fibers
}

Article in Textile Research Journal · October 2015

DOI: $10.1177 / 0040517515609259$

CITATION

1

3 authors, including:

Katarzyna Ewa Grabowska

Lodz University of Technology

24 PUBLICATIONS 99 CITATIONS

SEE PROFILE
READS

23

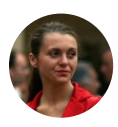

\section{Izabela Ciesielska}

North Carolina State University/Ghent Univer...

29 PUBLICATIONS 108 CITATIONS

SEE PROFILE

Some of the authors of this publication are also working on these related projects:

Project

Modelling of human body and protective textiles for estimation of skin sensorial comfort and life risk of fire-fighters working in extreme external conditions View project 


\title{
Micro-CT supporting structural analysis and modelling of ropes made of natural fibers
}

Textile Research Journal $0(00) 1-14$

(C) The Author(s) 2015

Reprints and permissions: sagepub.co.uk/journalsPermissions.nav DOI: I0.I I77/00405।75I5609259 trj.sagepub.com

@SAGE

\author{
Marta Toda', Katarzyna E Grabowska' and \\ Izabela L Ciesielska-Wrobel ${ }^{2,3}$
}

\begin{abstract}
This paper describes the modelling of the structure and mechanical parameters of rope components made of natural fibers. Modern X-ray micro-tomography (Micro-CT) was employed to measure the parameters of the internal structure of the multi-component yarns making up rope and utilized as a basic model of twisted rope. The results allowed calculation of the tensions generated in the component yarns and detection of the unevenness of the filling of the component yarns by fibers, which was clearly visible in cross-section. The unevenness of twist measured as a function of distance from the center of the yarn was also detected. The unevenness of fiber distribution in the twisted element decreased its intensity, starting from the surface of the yarn and going deeper into the structure. Migration of the fibers in the frame of the circumference of the component yarns was associated with the mutual slide of single fibers.
\end{abstract}

\section{Keywords}

fibers, rope, yarn, twisting, Micro-CT, tomography, fabrication

Modern ropes are highly specialized technical products, which are utilized in extremely demanding and varied conditions, e.g. the marine offshore industry and deep water installations, heavy lift slings, sailing, fishing, etc. ${ }^{1-3}$ Different ropes can be distinguished depending on their final application, technical parameters and construction. Common raw materials utilized for production of ropes are semi-aromatic (polyethylene terephthalate) and aromatic polyester (liquid-crystal polymers, especially Vectran), ${ }^{4,5}$ high-density polyethylene (HDPE, especially Dyneema and Spectra), 6,7 aromatic polyamides (Twaron, Technora and Kevlar), ${ }^{8}$ natural staple fibers (flax, hemp, cotton, jute, sisal) ${ }^{9}$ and metals (steel or its alloys). The nature of ropes made of wires and synthetic materials is relatively easy to predict as it depends mainly on the mechanical parameters of these materials. The interaction of elementary structural components of such ropes is limited compared with ropes made of natural raw materials, where the uneven linear density of the fibers and their structure, length and surface impact on the mechanical properties of the final product. Although ropes made of staple fibers have been used by humans since the development of fishery and shipping, they have not been characterized well mathematically. However, phenomena inside rope, namely tensions and friction between its components (fibers, threads), were noticed and described.

Until the middle of the twentieth century, most studies were on idealized staple fiber yarn, which was assumed to consist of a very large number of fibers of limited length, uniformly distributed in a uniform circular yarn. It was believed that the fibers were arranged in a helical pattern, following an idealized migration pattern, where each fiber followed a helical path, with

'Lodz University of Technology, Institute of Architecture of Textiles, Poland

${ }^{2}$ Ghent University, Department of Textiles, Belgium

${ }^{3}$ North Carolina State University, Textile Protection and Comfort Center, USA

\section{Corresponding author:}

Izabela L Ciesielska-Wrobel, Ghent University, Technologiepark 9079052 Zwijnaarde (Ghent), Belgium.

Email: izabela.ciesielskawrobel@ugent.be 
a constant number of turns per unit length along the yarn. In the second half of the twentieth century this approach started to shift in the direction of a theory describing fiber migration as less uniform. ${ }^{10-19}$ It has been demonstrated that if staple fibers in the threads are arranged uniformly in the ideal helical pattern, they will slip out along the thread (yarns) after applying tension to both ends of the thread. This breaks the continuity of the yarn structure..$^{20-22}$

The strength of the rope and the component yarns depend on the migration of staple fibers inside the yarn, which are not arranged along helical lines but migrate between different cross-sections of yarn. In other words, the arrangement of staple fibers in yarns is stochastic, but it is possible to describe this phenomenon using a probability density function.

Staple fibers migrate not only inside the structure of component yarns while they are produced, but also as a consequence of tensions working on the yarns. It is suspected that the level of migration of staple fibers in the component yarns depends on both tensions working on the component yarns and on the final number of twists per meter of the yarns. The magnitude of the real twist of staple fibers in the component yarns of the rope is based on the measurement of the helix pitch of the staple fibers on the surface of the yarn. This approach is questioned in this study, together with the application of the ideal helix as a model of the structure of component yarn.

It is possible to verify the internal structure of yarn/ rope using a non-invasive structure verification technique allowing identification of each single fiber's position, but no research has reported on this as yet.

The density distribution of the staple fibers of the filaments inside rope is also uneven and changes depending on the distance from the axis of the component thread. An invasive intervention is to pour resin on the thread and then cut it into segments, and one study has examined the resulting cross-sections under a microscope. ${ }^{23}$ However, this method is not accurate, because it does not allow the identification of the same fiber in the various cross-sections of the thread. The results of this study, although very interesting, are not precise and do not allow the mathematical identification of staple fiber density in the yarn. ${ }^{23}$

The application of X-ray micro-tomography (microCT) for identification of the structural internal parameters of rope allows the utilization of mathematical models for the verification of the phenomena inside the component yarns and between fibers, e.g. migration of the fibers owing to slide of fibers across each other.

The paper presents the results of studies on fivecomponent yarn as a simplified experimental model of twisted textile rope analyzed by the means of micro-CT.
Thus, the aims of this study are:

(a) identification of the phenomena which appear during the process of twisting the staple fibers and stretching the rope;

(b) making assumptions concerning ropes made of natural staple fibers;

(c) constructing a mathematical model describing the migration of the staple fibers in the twisting and stretching processes.

The following steps were taken to achieve these aims:

(a) analysis of the arrangement (position) of the staple fibers in relation to the longitudinal axis of the rope in the three-dimensional (3-D) coordinate system;

(b) analysis of the real twist distribution of the staple fibers at different distances from the axis of the component yarns and the axis of the whole rope;

(c) analysis of the packing density of the staple fibers in the whole rope in terms of their distance from the axis as in (b) and in the cross-section of the rope;

(d) analysis of the migration of the staple fibers during the twisting of components of the rope and the rope itself.

\section{Materials and methods}

Micro-CT uses X-rays to create cross-sections of a physical object that can be used to recreate virtual models without destroying the original object. Pixel sizes of the cross-sections are in the micrometer range. ${ }^{24,25}$ These pixel sizes have also resulted in the terms high-resolution X-ray tomography, micro-computed tomography (micro-CT or $\mu \mathrm{CT}$ ), and similar terms. Sometimes the terms high-resolution CT (HRCT) and micro-CT are differentiated ${ }^{26,27}$ but usually the term high-resolution micro-CT is used. ${ }^{26-28}$ Virtually all tomography today is computed tomography.

The penetration of the tested objects by X-ray provides greyscale images. The level of grey depends on the quantity of the radiation absorbed by the objects. The lighter the grey, the greater is the amount of radiation absorbed by the object. The raw images are subject to correction, which compensates for inhomogeneity and corrects X-ray beam hardening. The image reconstruction process begins by establishing the field of view (FOV). It is a matrix composed of pixels. The pixel is the smallest imaging unit in two dimensions (2-D). A voxel is the equivalent of a pixel in 3-D. Voxels are described as 3-D data blocks representing a specific $\mathrm{X}$-ray radiation. 
For each point (pixel) of the image a special coefficient is determined by the average values for all rays of the beam which passes through the pixel. This method is called a back projection technique.

The last stage is formation of the images' contours as a consequence of mathematical filtration. ${ }^{25-28}$ The sectional image reconstructed from measurements using a quantitative $\mathrm{CT}$ scanner is a linear map of the radiation absorption coefficient that makes up the scanned layer.

The test method relays on directing an X-ray beam on the object, and then the intensity of the radiation is recorded on the other side by detectors. This radiation is weakened by moving the object. Weakening is dependent on the radiation intensity and the type and thickness of the test object. Therefore, the change in radiation intensity of parallel beams of equal intensities passing through the test object can be calculated by:

$$
I=I_{0} e^{-\mu g}
$$

A linear attenuation coefficient $\mu$ is dependent on the atomic number and the density of the material object and it is characterized by the Bragg-Pierce law for the photoelectric absorption of a homogeneous piece of elemental matter ${ }^{16}$

$$
\mu=k \lambda^{3} Z^{3}
$$

Computed tomography distinguishes two basic types of projection systems. ${ }^{26,28}$

1. A system with a parallel beam - one obtains a flat (2-D) X-ray image of a single section. A 3-D image of the object can be obtained as a result of computer reconstruction of planar images.

2. A conical beam system. This system is characterized by the fact that the subject property is located on a movable table, which rotates $360^{\circ}$ and the lamp and the detector matrix remain stationary. Using a conical beam of radiation and detector arrays, and as a result of the full rotation of the object, we can obtain a cross-section of the entire facility. Next, using the Radon transform, 3-D image reconstruction of the object can be carried out. The system with the conical beam is most commonly used in industrial computed tomography thanks to the speed of calculations and image reconstruction.

The current studies used the conical beam system. Projection images obtained by scanning tomography must then transform or reconstruct the images. It can be done using two different methods: algebraic iterative or analytical. The study used a combination of analytical and iterative methods.
Iterative image reconstruction is based on the gradual displaying of an image which is that most similar to the real one. Similarity in this method is based, for example, on mean square error. The lower the value of the reconstruction error, the more faithful it is.

The analytical method is based on the application of the Radon transform and 2-D Fourier transform.

The Rodon transform of the image $f(x, y)$ is the following integral:

$$
R f(\theta, t)=\int f(x, y) \delta(x \cos (\theta)+y \sin (\theta)-t) \mathrm{d} x \mathrm{~d} y
$$

Using the Fourier transform allows us to pass from the spatial domain image $x, y$ to the frequency domain of complex numbers. The basis of the Fourier theory is the assertion that any signal that meets certain conditions can be decomposed into an infinite number of sinusoidal components, which are characterized by appropriate frequency, amplitude and phase. In practice, this signal is assessed by a few sinusoidal components. In the case of digital image analysis, 2-D discrete Fourier transform (Discrete Fourier Transform - DFT) is used.

As a result of the scanning of the object using a micro-CT and X-ray beam, one obtains a linear distribution of X-ray coefficient attenuation. Micro-CT test result is most often given as a map of the attenuation coefficients in X Hounsfield units (HU).

\section{Structure of a rope made of natural fibers}

Rope has an ability to bear significant tension along its length. The textile rope can be divided into two major groups: (a) braided ropes and (b) twisted ropes as well as (c) ropes for special purposes with a low twist per meter.

The most common, basic ropes are made of two, three or four yarns (strands) comprising several plies of threads twisted together. Each can have a different twist direction (Figure 1.)

First, natural fibers are twisted into yarn in a $Z$-direction. Next, these yarns are twisted in an $S$-direction, and finally twisted again with another component with $S$-direction into $Z$-direction.

An example of a four-yarn rope and its cross-section is presented in Figure 2.

\section{Model assumptions and simplifications}

In order to analyze the internal structure of the rope and the parameters influencing its ability to bear tension we utilized the structure of a multi-component rope as a model. This simplification was introduced after geometric assessment of the model and its physical 


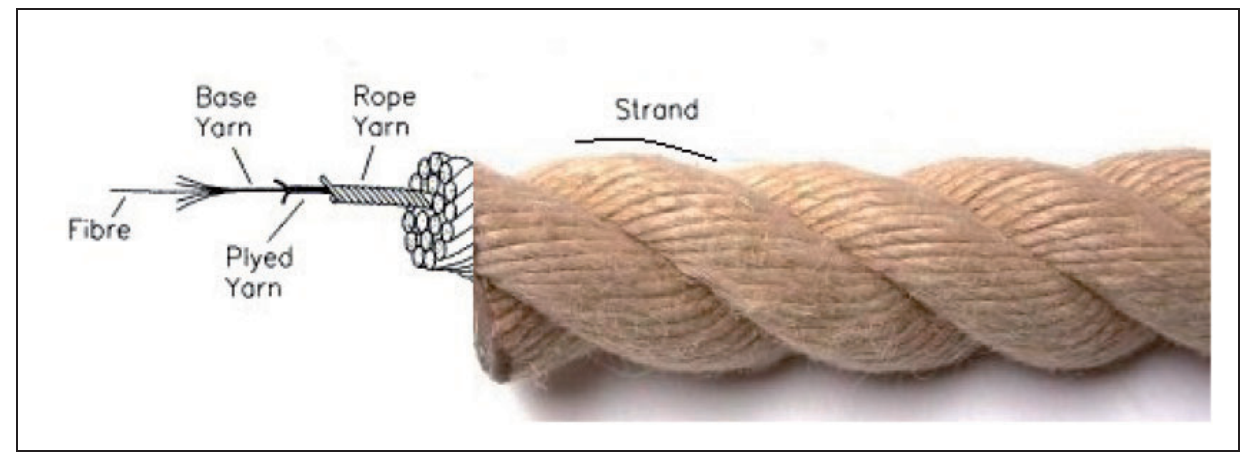

Figure I. Typical two-strand rope structure; image partly adapted from Leech. ${ }^{10}$

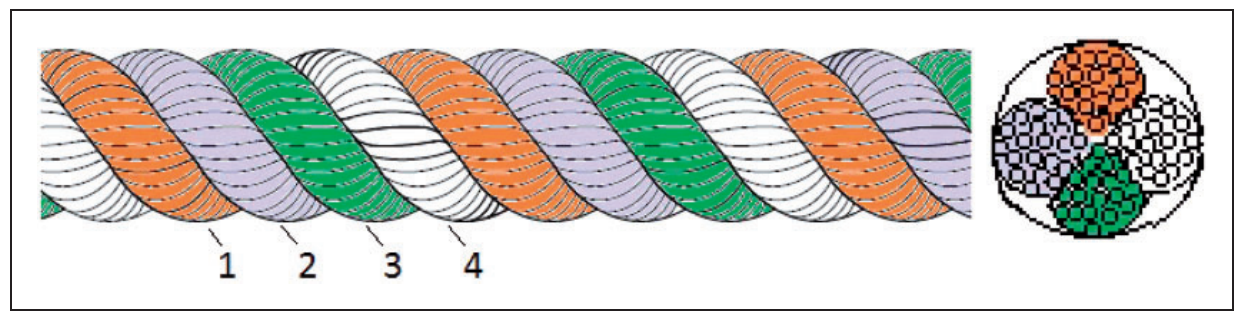

Figure 2. A four-strand rope structure showing the yarns and their cross-section.

properties using a finite element method. The simplified model was made of five component threads, each twisted in an $\mathrm{S}$ direction. The produced yarn is presented in Figure 3.

\section{Raw materials}

In order to produce 25 tex component yarn we utilized cotton fibers, which were twisted by applying $400 \mathrm{tpm}$. The diameter of a single fiber was $1.2 * 10 \mathrm{e}-6 \mathrm{~m}$ and its density was $1540 \mathrm{~kg} / \mathrm{m}^{3}$; the average length of the fibers was $0.02 \mathrm{~m}$. The maximum length of a single fiber in the thread was $0.037 \mathrm{~m}$ and the minimum length was $0.003 \mathrm{~m}$ ). The coefficient of friction was assumed to be 0.25 on the basis of other studies. ${ }^{29}$ The breaking force of the single fiber utilized to create the rope was $0.2 \mathrm{~N} /$ tex and its elongation while breaking was $5.5 \%$. The breaking force of the component thread was $0.12 \mathrm{~N} /$ tex and its elongation while breaking was $4.66 \%$. The final linear density of the whole rope was 129.4 tex. Its breaking force was $0.17 \mathrm{~N} /$ tex and its elongation while breaking was $7.29 \%$.

The twisting process of the five components was carried out when all the yarns were introduced into the twisting zone under the same conditions.

As a consequence of these production setting parameters, the core of the rope was empty. All five component yarns were positioned evenly around the circumference of the rope, as presented in Figure 4.

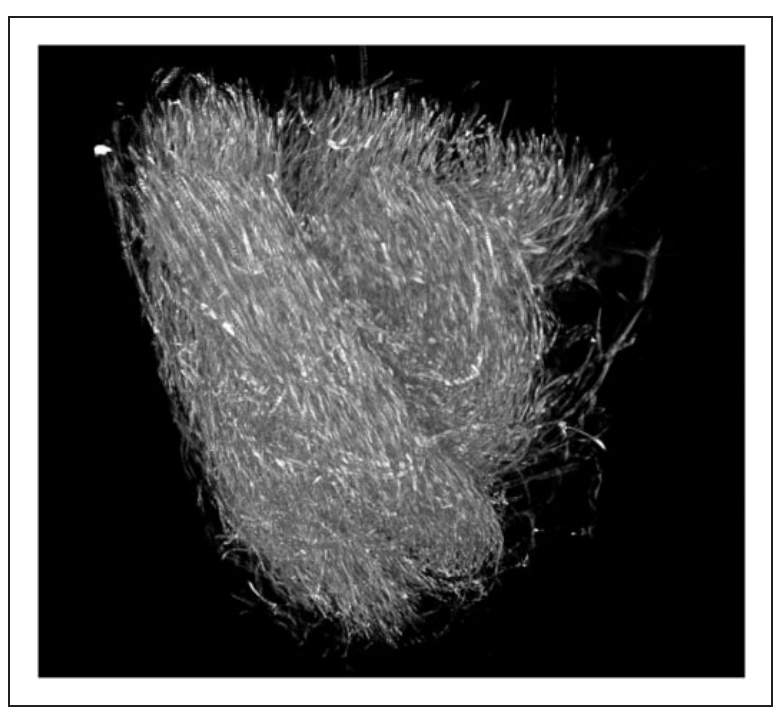

Figure 3. Visualization of the geometry of the produced yarns - a micro-CT image.

The core diameter was $12.86 \%$ of the whole rope diameter and the surface of this empty core was $31.85 \%$ out of the surface of the whole rope (assessment based on the image).

A five-component rope was tested according to the PN-EN ISO 2062:1997 standard. The test outcome is presented in Table 1. The test parameters are: $500 \mathrm{~mm} / \mathrm{min}$, tension $0,5 \mathrm{cN} /$ tex, sample length: $500 \mathrm{~mm}$. 
Figure 5 presents the change of tension in the rope depending on the displacement of its elements during a unidirectional static tension test. It was noted that under unidirectional static tension of the rope the breaking of all components took place at the same time.

\section{Structural parameters of a basic rope model and their impact on rope's durability}

Special stress was put on the structural unevenness of the analyzed rope model, inside which was an empty space with a radius of $r_{0}=4.5^{*} 10 \mathrm{e}-6 \mathrm{~m}$ (Figure 4.). The radius of the rope model, $R r$ was $3.5^{*} 10 \mathrm{e}-5 \mathrm{~m}$. The radius of a single yarn, $r$ twisted into the simplified rope model was $0.00015 \mathrm{~m}$. All these data were collected from micro-CT scans, which means that the measurements were taken based on the micro-CT scans. The resolution of the micro-tomography was $2.5 \mu \mathrm{m}$.

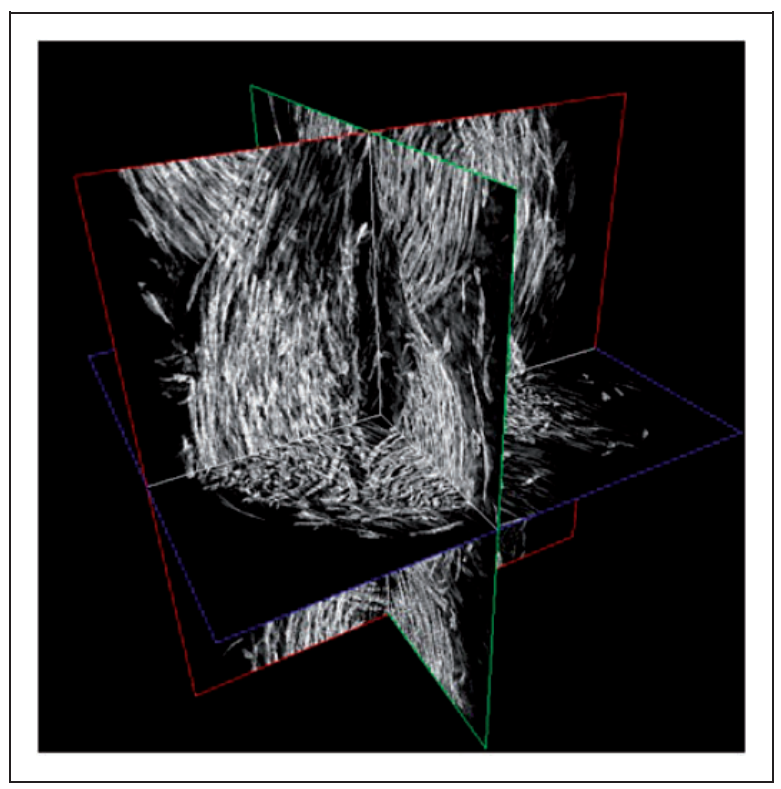

Figure 4. Distribution of fibers in the rope in threedimensional space.
Parameters affecting the durability of a rope made of staple fibers were described taking into consideration the structure of linear textile products. ${ }^{30}$ Longitudinal static stresses in component yarns forming the rope and durability of the basic rope model constructed of fivecomponent yarns were calculated, and the results were compared to the experimental findings. The study involved utilization of micro-CT scans to measure the structural parameters of the rope model, calculating, analyzing parameters that defined phenomena occurring on the level of staple fibers and component yarns and within the entire structure of the rope model during twisting and stretching.

First, analysis of the alignment of staple fibers in relation to the longitudinal axis of the rope model in a 3-D system of coordinates was conducted. Subsequently, the degree to which rope twist affects the twist of component fibers was determined. Equation (4), developed by Zimilki et al., ${ }^{31}$ was used

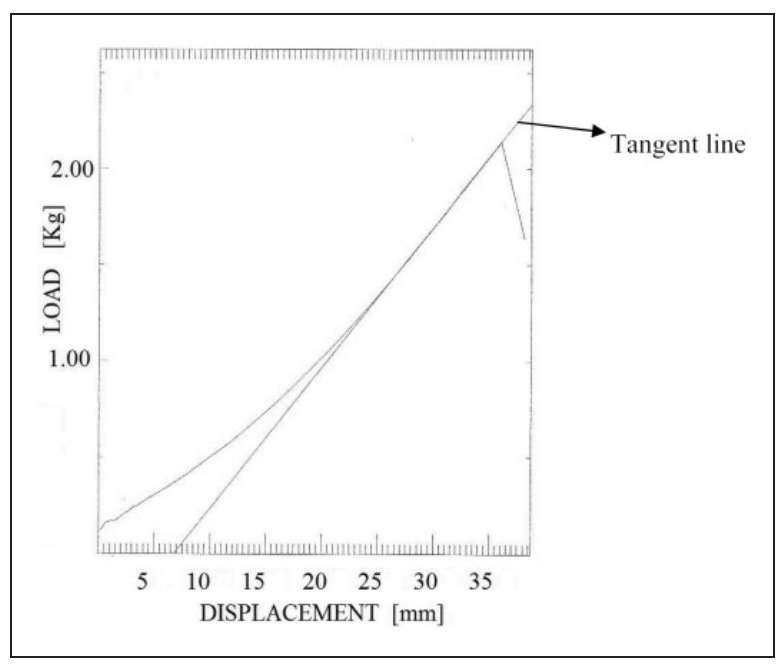

Figure 5. The load burden of the investigated rope versus the displacement of its elements during a unidirectional static tension test. All the components of the rope are identical so the curve on the graph represent the displacement for all these components.

Table I. Breaking force parameters collected during the tests performed on five-component rope with INSTRON model 4204

\begin{tabular}{llllllll}
\hline & $\begin{array}{l}\text { Displacement at } \\
\text { break [mm] }\end{array}$ & $\begin{array}{l}\text { Load at } \\
\text { break [cN] }\end{array}$ & $\begin{array}{l}\text { Strain at } \\
\text { break [\%] }\end{array}$ & $\begin{array}{l}\text { Displacement at } \\
\text { max load [mm] }\end{array}$ & $\begin{array}{l}\text { Load at max } \\
\text { load [cN] }\end{array}$ & $\begin{array}{l}\text { Strain at max } \\
\text { load [\%] }\end{array}$ & $\begin{array}{l}\text { Young } \\
\text { modulus [Pa] }\end{array}$ \\
\hline Mean & 36.50 & 2208 & 7.30 & 36.50 & 2208 & 7.30 & 601.30 \\
Standard deviation & 1.10 & 70.0 & 0.20 & 1.10 & 70.0 & 0.20 & 114 \\
Min & 34.0 & 2035 & 6.80 & 34.00 & 2035 & 6.80 & 563.30 \\
Max & 38.30 & 2349 & 7.70 & 38.50 & 2349 & 7.70 & 620.40 \\
CV & 3.00 & 3.20 & 3.00 & 3.00 & 3.20 & 3.00 & 1.90 \\
\hline
\end{tabular}

Average values based on 10 tests. 
to calculate the resultant twist generated in the component yarn when the yarn was twisted into a fivecomponent rope with an opposite twist to the component fiber. The resultant twist amounted to 174.39 twist $/ \mathrm{m}$ [tpm], which indicated that twisting the component yarn into a rope with an opposite twist caused a $56 \%$ loss of twist in the component yarn. Staple fibers in the outer layer of a single component yarn were tilted towards the longitudinal axis at an angle of $9.33^{\circ}$. The axis of a single component yarn was tilted towards the vertical axis of the rope model at an angle of $41.34^{\circ}$.

$$
t t=t d+(-) \frac{T}{4 \pi^{2} R r^{2} T^{2}+1}=174.39 \mathrm{tpm}
$$

Next, based on the tomographic image the following parameters of the thread were measured: according to formula presented by Żurek: ${ }^{30}$

- a nominal twist parameter $(g t)$ of a single component yarn twisted into rope, with the final twist 174.39 tpm

$$
g t=2 \pi r(t t)=0.1650
$$

$r=1.5^{*} 10 \mathrm{e}-5 \mathrm{~m}$, measurement based on the tomographic image;

- a nominal twist parameter $\left(g_{o}\right)$ of a single component yarn twisted with $400 \mathrm{tpm}$ (before its twisting into rope):

$$
g_{o}=2 \pi r_{o}\left(t t_{400}\right) \approx 0.25
$$

A shrink coefficient of a single component yarn created by twisting the component yarn using a twist of 174.39 twist $/ \mathrm{m}$ can be calculated from:

$$
S_{174}=2 /\left[1+\left(1+g^{2}\right)^{0,5}\right] \approx 1
$$

A shrink coefficient of a single component yarn created by twisting the component yarn using a twist of 400 twist $/ \mathrm{m}$ :

$$
S_{400}=2 /\left[1+\left(1+g_{o}^{2}\right)^{0,5}\right] \approx 1
$$

The linear density of the yarn after its twist into a rope can be calculated with the following formula:

$$
\begin{aligned}
T t= & T t_{\mathrm{o}} S_{400} / S_{174}=24,9659 \text { tex } \\
& (\text { according to laboratory measurements, } \\
& T t=25 \text { tex })
\end{aligned}
$$

When component yarns are twisted and stretched into a rope at the same time, component yarn narrowing occurs. The narrowing coefficient of a yarn is calculated from a formula developed for cotton yarn by Frydrych in $1995:^{32}$

$$
u=1.13-\frac{0.0265}{g}-0.12\left(100 a_{h}\right)^{0.25}=0.9
$$

$a_{h}$ The initial narrowing coefficient of a yarn is determined under the initial assumption that $a_{h}=a_{w}$, where $a_{w}$ is the relative elongation of a single staple fiber forming the component yarn. The initial elongation of a yarn was determined using a laboratory method. A sample yarn was collected from a band taken from the last stretcher of the fiber preparation stage. Once the approximate value of the narrowing coefficient is known, yarn elongation over the deceleration distance can be calculated according to the formula ${ }^{32,33}$

$$
a_{h}=\sqrt{\left(\frac{1+a_{w}}{\text { Stpm }}\right)^{2}-u^{2} g^{2}}-1=0.05
$$

The fiber in the component yarn alters the shape of the helix drawn by the yarn not only during rope twisting but also during stretching. The alteration parameter of the fiber axis shape is calculated according to formula: ${ }^{32}$

$$
k a=\frac{1+a_{h}}{u}=1.15
$$

Mean migration radius is based on micro-CT images according to the formula ${ }^{15}$

$$
r_{m}=\left(x^{2}+y^{2}\right)^{0.5}=9.5 \mathrm{e}-5 \mathrm{~m}
$$

The fiber migration parameter characterizes migration amplitude, and constitutes the quotient of absolute change in migration radius and the radius of a yarn:

$$
y a=\Delta r_{m} / r=0.07
$$

$\Delta r_{m}$ - increase in migration range (based on micro-CT images); $\Delta r_{m}=1.1 * 10 \mathrm{e}-6 \mathrm{~m}, r=1.5 * 10 \mathrm{e}-5 \mathrm{~m}$.

If no migration occurs, then $\Delta r_{m}=0$, and the migration parameter $y=0$.

If full migration occurs, the absolute increase in migration radius is equal to the radius of a yarn, i.e. $\Delta r_{m}=r$, and the migration parameter equals one.

In the analyzed basic rope model, the mean migration parameter indicates that the mean absolute change in migration range amounts to $7.3 \%$ of the yarn radius. 
The length of a single migration cycle was measured from an analysis of micro-CT images and equaled $Z_{l}=0.0045 \mathrm{~m}$.

The length of a fiber corresponding to one migration cycle is calculated according to a formula developed in 1969 by Hearle and colleagues ${ }^{13}$ for equivalent migration, i.e. migration with a constant turn, varying radius and the tilt angle of staple fibers corresponding to highest-intensity migration: ${ }^{14}$

$$
Q=\frac{1}{2}(1+\cos \beta) Z_{l} / \cos \beta=0.0045
$$

where:

$$
\beta=9^{\circ}
$$

Next, the parameter of stress reduction in component yarns should be calculated by taking into consideration the discontinuity of the fiber material, according to Hearle: ${ }^{14}$

$$
\beta=1-\frac{2}{3 L_{f}}\left[\frac{a Q}{2 \mu\left(1-\cos ^{2} \beta\right)}\right]^{\frac{1}{2}}=0.95
$$

where:

$$
\begin{aligned}
L_{f} & =0.02 \mathrm{~m} \\
a & =6^{*} 10 \mathrm{e}-7 \mathrm{~m} \\
\mu & =0.25^{29}
\end{aligned}
$$

In order to calculate the tensile stress in a single component yarn of a rope (without taking into consideration lateral stress from the neighboring component yarns of a rope, i.e. before the rope is twisted into the basic model), an equation developed by Frydrych is used: ${ }^{32}$

$$
\begin{aligned}
F= & \frac{2}{T t} k \pi \phi Q\left(\varepsilon_{f}\right)(r / g)^{2} \\
& \ln \frac{\left(1+y^{2} g^{2}+g^{2}\right)^{0.5}+\left(y^{2} g^{2}+k^{2}+g^{2}\right)^{0.5}}{\left(y^{2} g^{2}+1\right)^{0.5}+\left(y^{2} g^{2}+k^{2}\right)^{0.5}} \beta=1 \mathrm{~N} / \text { tex }
\end{aligned}
$$

where:

$$
\begin{aligned}
& Q\left(\varepsilon_{f}\right)+0.2 \mathrm{~N} / \text { tex } \\
& \phi \quad+198,636,235 / \mathrm{m}^{2}, \text { i.e. an average of } 140 \text { fibers in } \\
& \text { the cross-section of a single yarn) }
\end{aligned}
$$

In order to calculate the deceleration distance of component fibers during rope stretching, the frictional force affecting the fiber when the fiber is taken out of the static set of staple fibers present in a component yarn should be calculated per unit of fiber length, taking into account the lateral pressure coming from other component yarns in the rope. This is done by using a formula developed by Grabowska: ${ }^{21}$

$$
R=\frac{\mu \gamma_{f} u \pi 10^{5} F\left(1+e_{r}\right) \mathrm{d} T}{2 \sqrt{1+(D-d)^{2} \pi^{2} T^{2}}} \sin 2 \alpha=56.3 \mathrm{~N} / \mathrm{m}
$$

$$
\begin{aligned}
& \mu=0.25 ;^{29} \\
& \gamma=1540 \mathrm{~kg} / \mathrm{m}^{3.29} ; \\
& u_{d f}=1.2^{2} 10 \mathrm{e}-6 \mathrm{~m} ; \\
& e_{r}=-0.3 \% \\
& d=0.0003 \mathrm{~m} \\
& T=400 \mathrm{tpm} \\
& D=0.0007 \mathrm{~m} \\
& \alpha=41.34^{\circ}
\end{aligned}
$$

The deceleration length of the trapezoidal distribution of fibers was calculated with the formula: ${ }^{20}$

$$
l_{h}=\frac{l_{\max }}{2}-\frac{3}{4} \sqrt[3]{\frac{l_{\max }^{3}}{2}-3 \frac{A}{B}}=0.0056 \mathrm{~m}
$$

where:

$F_{S}$

$l_{\text {max }}=0.037 \mathrm{~m}$

$l_{\min }=0.003 \mathrm{~m}$

and

$$
\begin{gathered}
B=\frac{R\left(1-F_{s}\right) \cos \beta_{w k}}{l_{\max }^{2}-l_{\min }^{2}}=4906 \mathrm{~N} / \mathrm{m}^{3} \\
A=\left(1-0.75 C V_{f k}\right) f_{f k} T t_{f k}=0.034 \mathrm{~N}
\end{gathered}
$$

where:

$$
\begin{aligned}
& C V_{f k}=3 \% \\
& f_{f k}=0.2 \mathrm{~N} \\
& T t_{f k}=0.17 \text { tex }
\end{aligned}
$$

$l_{h}$ is a relatively high deceleration distance, present at both ends of a single fiber. Its characteristic feature is that stretching stress along this distance varies. This stress is always lower than the breaking stress of a single staple fiber. Consequently, staple fibers along this distance may slide between one another. In turn, the difference between the length of a single staple fiber and twice the length of the deceleration distance constitutes a section of the staple fiber where tensile stress affecting the fiber is constant. The limit value of this tensile stress corresponds to the value of the breaking stress of a single staple fiber. This section of the fiber is also where breaking occurs. 
The percentage of staple fibers which slide over each other in a single component yarn during the stretching process was estimated with the following formula (assuming that all the staple fibers had the same length) ${ }^{21,22}$

$$
n_{S l}=\frac{l_{h}}{L_{f}} 100 \%=28 \%
$$

where:

$$
l_{h}=0.0056 \mathrm{~m}
$$

Assuming that all the staple fibers have the same length, in the analyzed model of unidirectional tensile static test, the sliding of fibers takes place $(28 \%$ of the fibers) and the rest of the fibers (72\%) are engaged by another fiber and subsequently broken during the tensile test.

Tensions aroused in the elongation of the single component yarn at the breaking moment can be calculated with the following formula: ${ }^{21}$

$$
\begin{aligned}
S= & \frac{R\left(1-F_{s}\right) l_{h} \cos \beta_{w k}}{T t_{f k}\left(l_{\max }^{2}-l_{\min }^{2}\right)^{2}} \\
& \times\left\{l_{\max }^{4}-4 l_{h} l_{\max }^{3}+8\left(l_{h}^{2} l_{\max }^{2}-l_{h}^{3} l_{\max }\right)+\frac{48}{15} l_{h}^{4}\right\} \\
= & 0.1225 \mathrm{~N} / \mathrm{tex}
\end{aligned}
$$

A partial derivative of the elongation of the component yarn with respect to a rope elongation can be calculated with the following formula: ${ }^{21}$

$$
\frac{\delta e}{\delta e_{l}}=\frac{\cos \alpha_{k 0}}{\cos \alpha_{k}}\left[\frac{\sin \alpha_{k}}{\cos \alpha_{k}}\left(1+e_{l}\right) \frac{\delta \alpha_{k}}{\delta e_{l}}+1\right]=0.7875
$$

where:

$$
\begin{aligned}
& e_{l}=7.29 \%, \\
& \alpha_{k 0}=41.34^{\circ}, \\
& \alpha_{k}=25^{\circ}
\end{aligned}
$$

$$
\delta \alpha_{k} / \delta e_{l}=-0.11 \text {. }
$$

The breaking force of the rope can be calculated with the following formula: ${ }^{21}$

$$
P=5 S \frac{T t}{T t_{l}} \frac{\delta e}{\delta e_{l}} \sec \alpha_{k 0}=0.124 \mathrm{~N} / \mathrm{tex}
$$

where:

$$
T t_{l}=129.4 \text { tex. }
$$

The static tensile strength of the unidirectional longitudinal rope model obtained in the experiment is $0.17 \mathrm{~N} /$ tex.

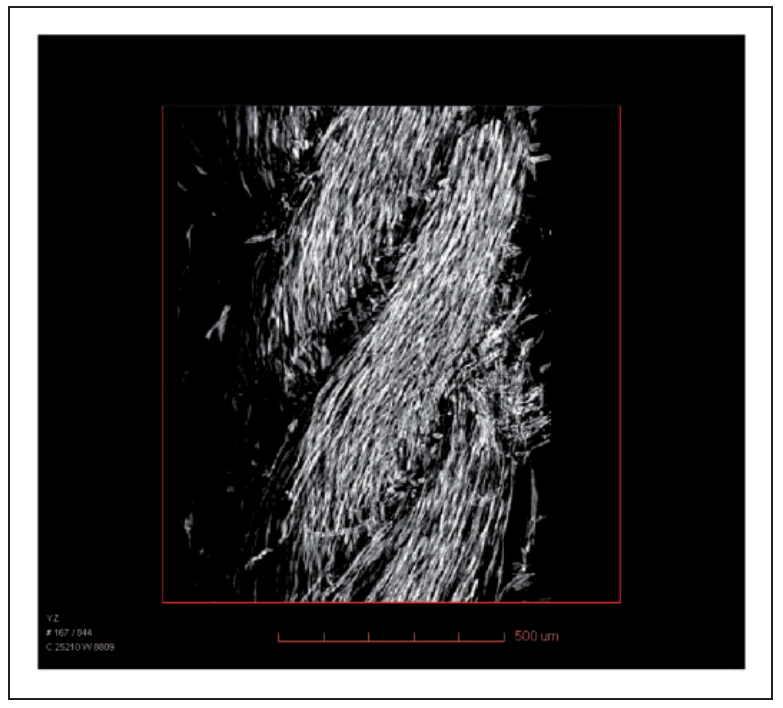

Figure 6. A longitudinal section of the rope made in the $2 / 3$ of the radius.

\section{Identification of phenomena occurring during staple fiber twisting in the basic model of a rope}

The tilt angle of staple fibers towards the longitudinal axis of the rope model is $32.01^{\circ}$ on the surface, i.e. $3.5^{*} 10 \mathrm{e}-5 \mathrm{~m}$ away from the center of the rope model, whereas the actual tilt angle of staple fibers on the external surface of a component yarn is $9.33^{\circ}$. This figure is based on the tilt angle of a single component yarn towards the longitudinal axis of the rope model:

$$
41.34^{\circ}-32.01^{\circ}=9.33^{\circ}
$$

This means that the twist of a single component yarn measured based on the tilt angle of staple fibers on the outer surface of the rope model is given by:

$$
T_{z}=\operatorname{tg} \beta_{o} / 2 \pi r=174.31 \mathrm{tpm}
$$

where:

$$
\begin{aligned}
& \beta_{o}=9.33^{\circ}, \\
& r=1.5^{*} 10 \mathrm{e}-5 \mathrm{~m}
\end{aligned}
$$

Subsequently, a micro-CT image of the rope model (Figure 6) was used to measure the tilt angle of staple fibers towards the longitudinal axis of the rope at twothirds of the radius of the basic rope model (from the center of the rope), i.e. $0.00022 \mathrm{~m}$ away from the center of the rope model and, simultaneously, at $r_{o}=3.7^{*} 10 \mathrm{e}-6 \mathrm{~m}$ away from the center of a single component yarn, i.e. at one-quarter of the radius of a single component yarn away from the center of the yarn. The tilt angle of staple fibers towards the longitudinal axis of the rope model amounted to $38.39^{\circ}$. 


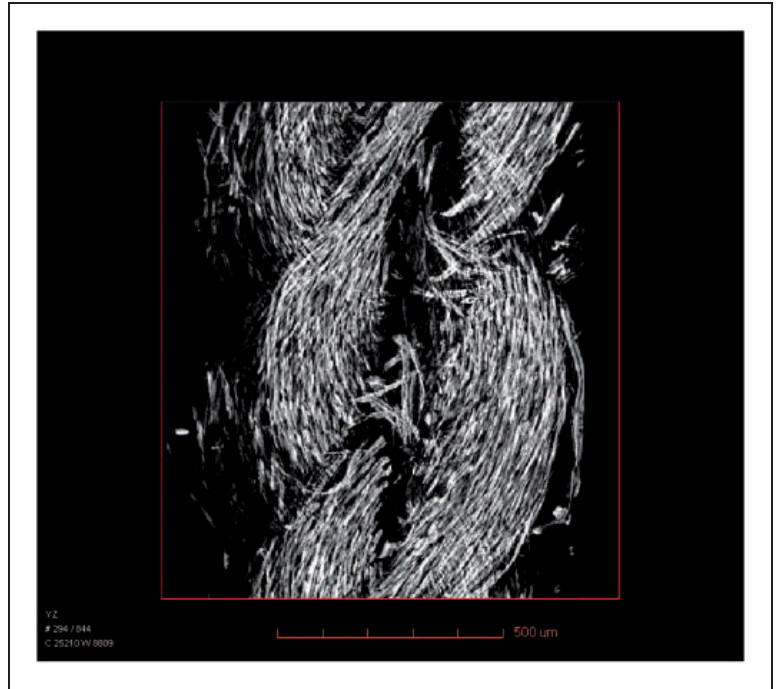

Figure 7. A longitudinal section of the rope made in the $1 / 3$ of the radius.

In other words, the tilt angle of staple fibers in a component yarn is given by the expression:

$41.34^{\circ}-38.38^{\circ}=2.96^{\circ}$

This indicates that staple fiber migration at a distance of one-quarter of the radius of a single component yarn away from its center is intense. This is given by:

$$
T_{1 / 4}=\operatorname{tg} \beta_{1 / 4} / 2 \pi r_{1 / 4}=220 \mathrm{tpm}
$$

where:

$\beta_{1 / 4}=2.96^{\circ}$,

$r_{1 / 4}=3.7 * 10 \mathrm{e}-6 \mathrm{~m}$

At a distance of one-third of the rope radius (Figure 7), i.e. $1.1 * 10 \mathrm{e}-5 \mathrm{~m}$, staple fibers are tilted at a $36.196^{\circ}$ angle. This constitutes the tilt angle of staple fibers in a component yarn inside the rope towards the longitudinal axis of the rope. Figure 8 presents a longitudinal section of the rope made along its diameter. In turn, the tilt angle of staple fibers in a component yarn towards the axis of a yarn tilted at a $41.34^{\circ}$ angle towards the longitudinal axis of the rope amounts to $5.14^{\circ}$ on the surface inside the rope, according to the expression:

$41.34^{\circ}-36.196^{\circ}=5.14^{\circ}$

Thus, staple fibers display a lower twist inside the rope than on the outer surface of the rope. The twist inside the rope equals $95.54 \mathrm{tpm}$, according to the following expression:

$$
T_{w}=\operatorname{tg} \beta_{o} / 2 \pi \mathrm{r}=95.54 \mathrm{tpm}
$$

where:

$$
\begin{aligned}
& \beta_{o}=5.14^{\circ}, \\
& r=1.5^{*} 10 \mathrm{e}-5 \mathrm{~m}
\end{aligned}
$$

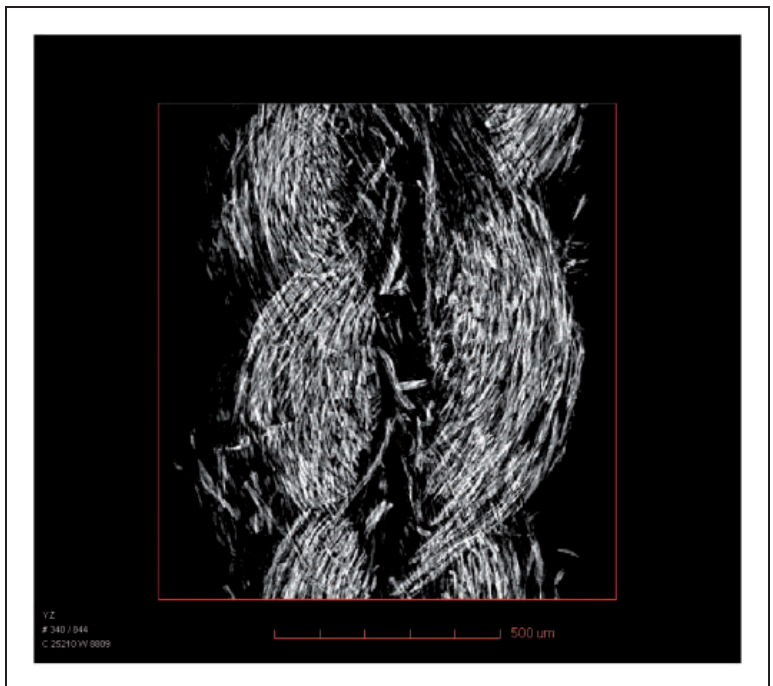

Figure 8. A longitudinal section of the rope made along a diameter.

A $45 \%$ reduction of fiber twist occurs on the surface of a component yarn inside the rope. This indicates that the rope axis follows a sine curve in space. The model of the five-component rope is hollow at the center. The radius of the hollow core equals $4.2 * 10 \mathrm{e}-6 \mathrm{~m}$. Figure 9 shows changes in the tilt angle of staple fibers depending on distance from the center of the rope.

\section{Analysis of packing density distribution of staple fibers in the cross-section of the basic rope model}

The cross-section of the rope model composed of five component yarns (Figure 10) forms a circle with a diameter more than twice as big as the diameter of a single component yarn. The cross-section of a single component yarn resembles an equilateral triangle with its longest side equal to one-fifth of the circumference of the rope model. The cross-section of a single component yarn was found to contain on average 140 staple fibers. Furthermore, staple fiber packing density in the cross-section of the rope yarn taken as the basic rope model was found to be uneven. The highest staple fiber packing density in the cross-section of the basic rope model was found in the vicinity of the hollow core of the rope model. When the multi-component yarn taken as the basic rope model was being twisted, staple fibers migrated towards the center of the model. Figure 11 shows staple fiber packing density as a function of the distance from the center of the model. The cross-section of the rope was divided into three circles, each with a surface area of $10 \mathrm{e}-8 \mathrm{~m}^{2}$ (the inner circle, corresponding to the hollow core of the rope, was disregarded). 


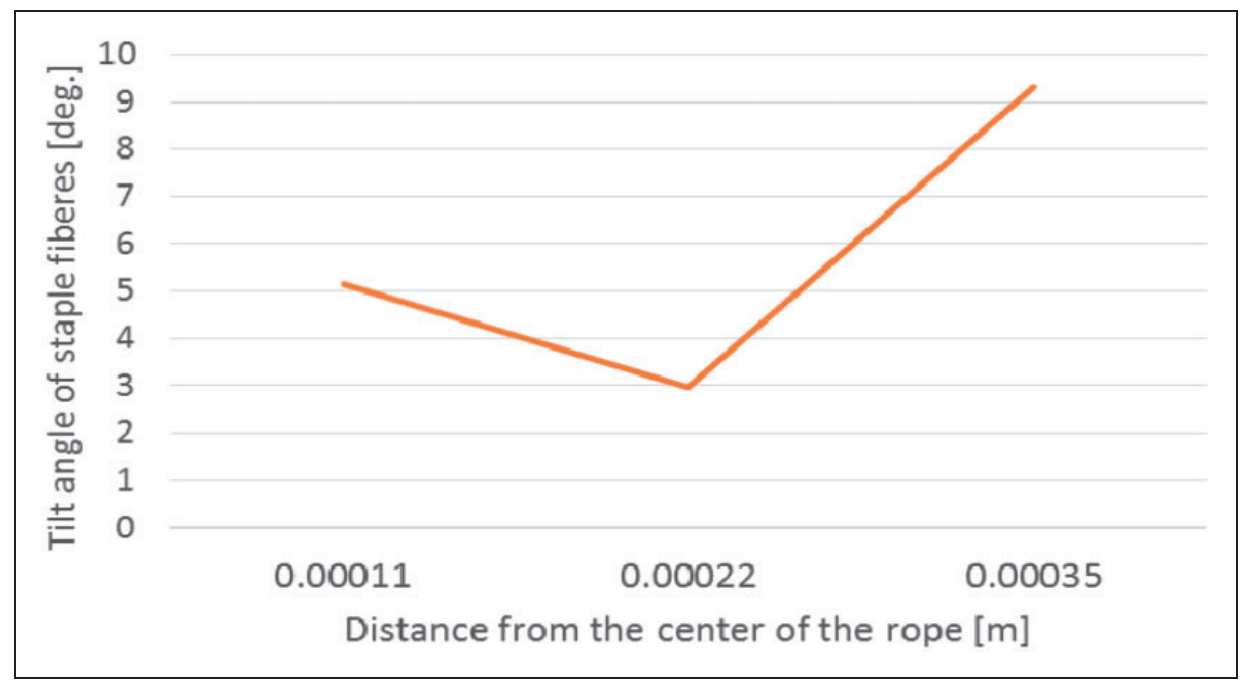

Figure 9. The dependence between the tilt angle of the staple fibers and their distance from the center of the rope.

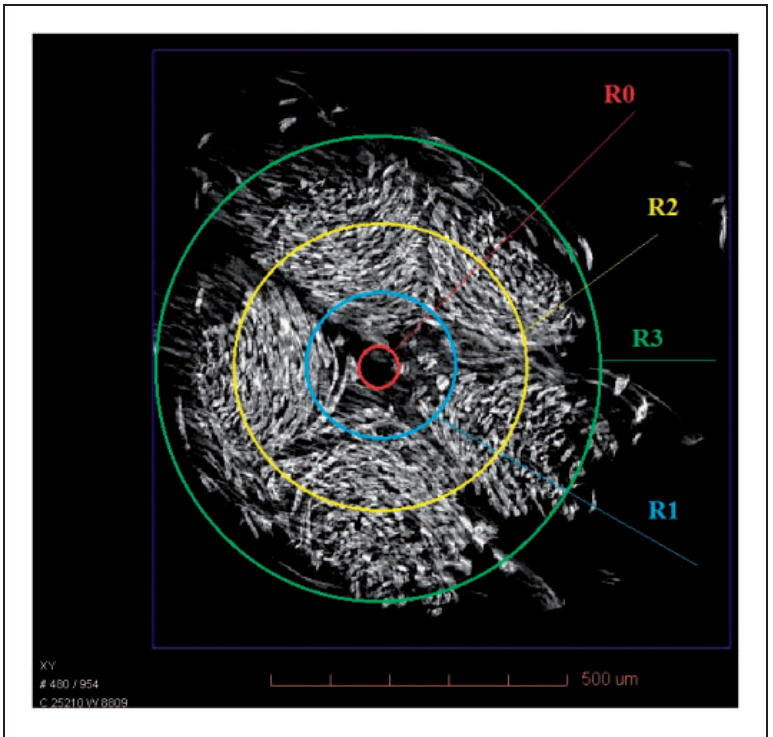

Figure 10. A cross-section of the rope model.

The limit of each circle is given by the following radii of the rope model:

- $\mathrm{R} 0=4.5^{*} 10 \mathrm{e}-6 \mathrm{~m}$ - radius of the hollow core of the rope;

- $\mathrm{R} 1=2.4^{*} 10 \mathrm{e}-5 \mathrm{~m}$ - radius describing the ring nearest to the center of the rope model;

- $\mathrm{R} 2=3 * 10 \mathrm{e}-50 . \mathrm{m}-$ radius describing the second ring in the rope model;

- $\mathrm{R} 3=3.5^{*} 10 \mathrm{e}-5 \mathrm{~m}-$ outer radius of the rope model.

Analysis of Figure 10 found that the cross-sections of individual component yarns twisted into the basic

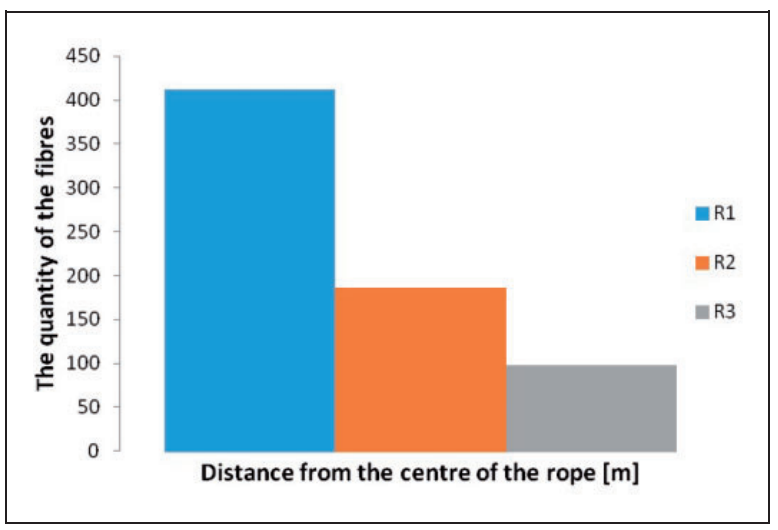

Figure II. Distribution of the packing density of staple fibers in the rope model cross-section.

rope model showed uneven packing density of staple fibers, i.e. the highest packing density occurred at the apex of the equilateral triangle formed by the crosssection of a single component yarn. In other words, $60 \%$ of staple fibers are located in the inner ring, designated by $2.4 * 10 \mathrm{e}-5 \mathrm{~m}$ radius. This group of staple fibers transfers the greatest longitudinal stress that stretches the basic rope model. Packing density of staple fibers decreases towards the outer surface of the model, with only $14 \%$ of all staple fibers located in the outer ring. This group of fibers transfers the compressive stress which occurs in the cross-section of the model.

Research on single yarns ${ }^{17-19,34}$ indicates that the highest staple fiber packing density in single yarns occurs in the inner ring, which means that staple fibers in single yarns migrate towards the center of the rope when they are twisted into a rope. This phenomenon may be referred to as secondary migration. 
Analysis of staple fiber migration during the twisting of a single yarn followed by the twisting of a rope

Research based on micro-CT images suggests that component yarns forming the rope model do not migrate. In other words, they maintain their position along the entire length of the rope, i.e. they are tilted at a $41.34^{\circ}$ angle towards the longitudinal axis of the rope model, with a radius described by the axis of each yarn equal to $1.2 * 10 \mathrm{e}-5 \mathrm{~m}$. This is consistent with Hearle and Merchant, ${ }^{15}$ who stated that if component yarns are subjected to equal stretching during twisting they do not migrate. On the other hand, if any yarn enters the twisting zone with what is referred to as an excess, i.e. without being subjected to stretching, it will migrate. The more yarns that enter the twisting zone without being subjected to stretching, the more intense is the yarn migration within the rope. The subsequent stages of research involved analysis of stimulated component yarn migration caused by some component yarns entering the twisting zone with an excess, i.e. without initial stretching.

However, analysis of micro-CT images suggests that staple fibers in component yarns migrate owing to the process of twisting component yarns into the rope. This can be seen in Figure 10, which shows a clear disturbance to the circular shape of the cross-section of a single component yarn and varied fiber packing density of fibers depending on distance from the center of the rope model. Note that this is secondary migration, occurring when component yarns are twisted into the rope model. Primary migration of staple fibers took place when the fibers were twisted into a single component yarn. Further research involved analysis of primary staple fiber migration when fibers were twisted into a single component yarn.

Hearle $^{12}$ listed the following parameters that characterize staple fiber migration, the values of which were calculated from micro-CT images of the rope model:

- Mean radial position of a staple fiber relative to the radius of a single yarn, i.e. migration range:

$$
Y=\sum\left(r_{i} / r\right) / n_{i}=0.630
$$

where:

$$
\begin{aligned}
& r_{i}=\left(x_{i}^{2}+y_{i}^{2}\right)^{0.5}=9.50 \mathrm{e}-5 \mathrm{~m} \\
& r=1.5^{*} 10 \mathrm{e}-5 \mathrm{~m} .
\end{aligned}
$$

Thus, the mean radius of staple fiber migration amounts to $63.55 \%$ of the radius of a yarn.

- The distribution function of the radial position of a yarn:

$$
D_{f}=\left[\sum\left(Y_{i}-Y\right)^{2} / n_{i}\right]^{1 / 2}=0.12
$$

and the coefficient of variation of radial yarn position:

$$
C V=D / Y=4.7 \%
$$

- Migration intensity measured as the relationship between the radial position of a yarn to the migration length of that yarn:

$$
I m=\left[\sum\left(\mathrm{d} Y_{i} / d z\right)^{2} / n_{i}\right] 1 / 2=218.97 / \mathrm{m}=2.19 / \mathrm{cm}
$$

Thus, mean migration period equals $0.0045 \mathrm{~m}$.

The analyzed migration corresponds to the twist of staple fibers determined at one-quarter of the radius of a single yarn and indicates that staple fibers located at this distance from the yarn center are characterized by the most intense migration, which determines the durability of the rope.

\section{Conclusions}

1. Simultaneous introduction of five components into yarns into the twisting zone causes placement of all of them along the circumference of the rope. The core of the rope remains empty; all the components bear the same tension and are subject to destruction at the same moment when the tension applied exceeds the limit (breaking force).

2. The calculated breaking distance of staple fibers proves that the breaking force overrides the sliding of fibers and the proportion is $72 \%$ to $28 \%$, respectively.

3. A cross-sectional deformation of each single component yarn takes place when they are twisted to form a rope. The cross-section of the single thread components is roughly the shape of an isosceles triangle with an angle directed towards the interior sharp line.

4. A secondary migration of staple fibers was detected. It was attributable to the twisting of the component yarns and formation of the rope. When yarns made of staple fibers are twisted, these component yarns tend to migrate towards the interior of the rope. Up to $60 \%$ of staple fibers forming the rope are placed in the internal ring - between the empty core of the rope and three radii. This group of staple fibers bears the tensions working on the rope.

5. The packing density of the staple fibers in the crosssection of the model of the rope decreases from the center of the rope towards the exterior of the rope. The density of packing of staple fibers in the crosssection of the rope decreases in the direction from 
the center to the external surface of the rope. The outer ring of the rope model contains up to $14 \%$ of all staple fibers. This group of fibers bears the compressive stresses in cross-section.

6. The greatest migration of staple fibers takes place in a quarter of the radius of the single component thread. The calculated intensity of migration is $2.19 / \mathrm{cm}$ and even the shortest fibers in this layer migrate to other layers.

7. A new methodology of verification of structure of ropes, micro-CT, was employed to measure the parameters of the internal structure of the multi-component yarns. Although the application of this new method was challenging, owing to settlements of the system, it did make it possible to obtain very precise measurements and imaging, allowing tracing fibers.

\section{Declaration of conflicting interests}

The authors declared no potential conflicts of interest with respect to the research, authorship, and/or publication of this article.

\section{Funding}

This work was elaborated in the framework of project 'Basic Researches on Construction of Space Cable' (ID: 147886, No: 2011/01/B/ST8/03848) funded by National Centre of Science. The last author is grateful to the European Union, the 7 th European Framework, Marie Curie International Outgoing for financing the Magnum Bonum project (grant number 622043).

\section{References}

1. Fillep S, Mergheim J and Steinmann P. Computational homogenization of rope-like technical textiles. Comput Mech 2015; 55: 577-590. DOI 10.1007/s00466-015-1124-7.

2. Smeets P, Jacobs M and Mertens M. Creep as a design tool for HMPE ropes in long term marine and offshore applications. In: OCEANS, 2001. MTS/IEEE conference and exhibition, Honolulu, HI, USA; vol. 2.

3. Sack P and Schuetzner K. Use of high modulus fiber ropes in large scale towed marine applications. In: OCEANS 1999. MTS/IEEE. Riding the crest into the 21st century, Seattle, WA, USA; vol. 2.

4. Beers DE and Ramirez JE. Vectran high-performance fibre. J Text Inst 1990; 81(4): 561-574. DOI: $10.1080 /$ 00405009008658729.

5. Vectran material characteristic. http://www.vectranfiber. com/Home.aspx (accessed 19 March 2015).

6. Dyneema lines and ropes characteristic. http:// www.dsm.com/products/dyneema/en_US/applications/ ropes-and-lines.html (accessed 19 March 2015).

7. Spectra fibers characteristic. http://www.honeywell-advan cedfibersandcomposites.com/applications/rope/ (accessed 19 March 2015).
8. Phillystran ${ }^{\circledR}$ Four Strand Mooring Ropes-Kevlar ${ }^{\circledR} /$ Twaron $^{\circledR} /$ Technora $^{\circledR}$ (Aramid) Rope, characteristic of ropes made of different raw materials http://phillystran. com/product-catalog/Four-Strand-Mooring-Ropes-Kev lar-Twaron-Technora (accessed 19 March 2015).

9. Hearle JWS, Lomas B and Cooke WD. Atlas of fibre fracture and damage to textiles. 2nd ed. Cambridge, UK: Woodhead Publishing, 1998. Online version available at: http://app.knovel.com/hotlink/toc/id:kpAFFD TE0A/atlas-fibre-fracture/atlas-fibre-fracture.

10. Leech CM. The modelling and analysis of the mechanics of ropes, series solid mechanics and its applications. Dordrecht: Springer, 2014.

11. Hearle JWS. The mechanics of twisted yarns. the influence of transverse forces in tensile behavior. $J$ Tex Inst 1958; 49: 389-408.

12. Hearle JWS, El-Behery HMA and Thakur VM. The mechanics of twisted yarns theoretical developments. J Tex Inst 1961; 52: 197-220.

13. Hearle JWS, Gupta BS and Merchant VB. Migration of fibres in yarns. Characterization and idealisation of migration behaviour. Text Res $J$ 1969; 35: 329-334.

14. Hearle JWS and Bose ON. Migration of fibres in yarns, a geometrical explanation of migration. Text Res J 1965; 35: 693-699.

15. Hearle JWS and Merchant VB. Interchange of position among the components of a seven - ply structure: mechanism of migration. J Tex Inst 1962; 53(12): 537-552.

16. Hearle JWS. Theoretical analysis of the mechanics of twisted staple fiber yarns. Tex Res J 1965; 35: 1060-1071.

17. Hearle JWS and Sakai T. On the extended theory of the mechanics of twisted yarns. J. Textile. Mach. Soc. Japan, 31, 1978, $126-131$.

18. Van Langenhove L. Simulating the mechanical properties of a yarn based on the properties and arrangement of its fibres. The finite element model. Text Res J 1997; 67(4): 263-268.

19. Van Langenhove L. Simulating the mechanical properties of a yarn based on the properties and arrangement of its fibers. Results of simulation. Text Res J 1997; 67(5): 342-347.

20. Van Langenhove L. Simulating the mechanical properties of a yarn based on the properties and arrangement of its fibres. Practical measurement. Text Res J 1997; 67(6): 406-412.

21. Grabowska KE. Mathematical modeling of tensile properties of fancy loop yarns. Theoretical part I. Tex Res J 2010; 80(18): 1905-1917.

22. Grabowska KE. Experimental analysis of the tensile properties of fancy loop yarns part II. Text Res J 2010; 80(18): 1917-1930.

23. Grabowska KE. Mathematical basis for classification of twisted multiplied fancy yarns. Text Res J 2010; 80(17): 1768-1777.

24. Martindale JG. A new method of measuring the irregularity of yarns with some observations on the origin of irregularities in worsted slivers and yarns. J Text Inst 1945; 36: 35-47.

25. Siczek M. Computer tomography and magnetic resonance for students of information technology (published in 
Polish: Tomografia Komputerowa i Rezonans Magnetyczny dla studentów kierunku Informatyka). Lublin: UMCS, 2011.

26. Lewińska-Romicka A. Noninvasive studies. The basis of methods of measurements of defects (published in Polish: Badania nieniszczace. Podstawy defektoskopii). Warszawa WNT, 2001.

27. Kielczyk J. Industrial radiography (published in Polish: Radiografia przemystowa). Warsaw: Wyd. Gamma, 2006.

28. Rajczyk E. CT Computed tomography in industrial applications. Part 1. The idea, measurements, the main components and their functions (published in Polish: Tomografia komputerowa CT w zastosowaniach przemysłowych. Cz.I. Idea pomiarów, główne zespoły i ich funkcje. Mechanik 2001; 2.

29. Grupta BS. Friction in textile materials. Cambridge, UK: Woodhead Publishing, 2008.

30. Zurek W. The structure of linear textiles (published in Polish: Struktura liniowych wyrobów wlókienniczych). Warsaw, WNT, 1989.

31. Zimilki DA, Kennedy JM, Hirt D, et al. Determining mechanical properties of yarns and two - ply cords from single filament data. model development and prediction. Tex Res $J$ 2000; 70(11): 991-1004.

32. Frydrych I. An unidirectional tensile model based on conventional cotton yarns (published in Polish: Model wytrzymalości przy jednokierunkowym rozciaganiu klasycznych przędz bawelnianych) W.P.L.,1995, doi: 10.1243/03093247V301045.

33. Cherif Ch, Seidel A, Younes A, et al. Evaluation of a tensile test for the determination of the material behavious of filament yarns under high strain rates. Autex Res J 2010; 10(4): 88-94.

34. Toda M and Grabowska K Computed Microtomography in the analysis of fiber migration in yarn. Autex Res $J$ 2013; 13(1): 28-32.

\section{Appendix}

\section{Notation}

$A, B$ numerical parameters

$a$ radius of single staple fiber (measurement based on the microscopic assessment)

$a_{h}$ an elongation over the deceleration distance

$a_{w}$ the relative elongation of a single staple fiber forming the component yarn

$C V$ coefficient of variation of radial yarn position

$C V_{f k} \quad$ coefficient of variation of the breaking force of a single staple fiber
$D$ external diameter of the helix drawn by a component yarn in the rope

$D_{f}$ distribution function of the radial position of a yarn

$d$ diameter of a component yarn under initial load

$e_{1}$ a longitudinal deformation of the rope

$e_{r}$ relative deformation of yarn diameter

$F$ a tensile stress in a single component yarn of a rope (without taking into consideration lateral stress from the neighboring component yarns of a rope)

$F_{s}$ proportion of staple fibers with a length lower than the minimal length of fibers in a band

$f(x, y)$ a function describing the distribution of the radiation absorption

$f_{f k}$ breaking stress of a single staple fiber

$g$ thickness of the studied material

$g_{o}$ a nominal twist parameter of a single component yarn twisted with 400 twists/m (before its twisting into rope)

$g_{t}$ a nominal twist parameter

$I$ intensity (power per unit area) of the radiation transmitted through the object

$I_{0} \quad$ initial intensity of the radiation

Im migration intensity measured as the relationship between the radial position of a yarn to the migration length of that yarn

$k$ the coefficient of proportion

$k a$ the alteration parameter of the fiber axis shape

$L_{f}$ mean length of staple fiber forming the yarn

$l_{h}$ deceleration length of the trapezoidal distribution of fibers

$l_{\max }$ maximal length of fibers in a band

$l_{\min }$ minimal length of staple fibers in a band

$n_{\mathrm{S} 1}$ the percentage of staple fibers which slide over each other in a single component yarn during the stretching process

$n_{i} \quad$ number of the fibers

$P$ breaking force of the rope

$Q$ the length of a fiber corresponding to one migration cycle

$Q\left(\varepsilon_{f}\right) \quad$ breaking stress of a single component fiber

$R$ the deceleration distance of component fibers during rope stretching 
$R r \quad$ radius of the rope (measurement based on tomographic image)

$r$ a mean radius of a single yarn in the rope

$r_{i}$ migration radius

$r_{1 / 4}$ one-quarter of the radius of a component yarn

$\mathrm{rm}$ a mean migration radius

$r_{o}$ a radius of a single yarn before its twisting into rope (measurement based on tomographic image, $\left.r_{o}=0.0001 \mathrm{~m}\right)$

$S$ tension aroused in the elongation of the single component yarn at the breaking moment

$S_{174}$ a shrink coefficient of a single component yarn created by twisting the component yarn using a twist of 174.39 tpm

$S_{400}$ a shrink coefficient of a single component yarn created by twisting the component yarn using a twist of $400 \mathrm{tpm}$

$S_{\text {tpm }}$ a shrink coefficient of a single component yarn created by twisting the component yarn using a specific amount of tpm

$T$ initial twist given to cotton fibers (according to laboratory measurements)

$\operatorname{Tr}$ rope twist

$T t$ the linear density of the yarn after its twist into a rope

$T t_{f k} \quad$ linear density of a single staple fiber

$T_{1 / 4}$ fiber migration at a distance of onequarter of the radius of a single component yarn away from its center

$T t_{0}$ a linear density of the single component yarn before it was twisted into a rope

$T t_{1}$ linear density of the modelled rope

$T w$ the twist inside the rope equals

$T z$ the twist of a single component yarn measured based on the tilt angle of staple fibers on the outer surface of the rope model

$t$ twist of a single component yarn before its twisting in the rope (according to laboratory measurements $(t=400$ tpm $)$

$t d$ distance from the beginning of the system of coordinates

tt 400 a twist in a component yarn before it has been twisted in a rope

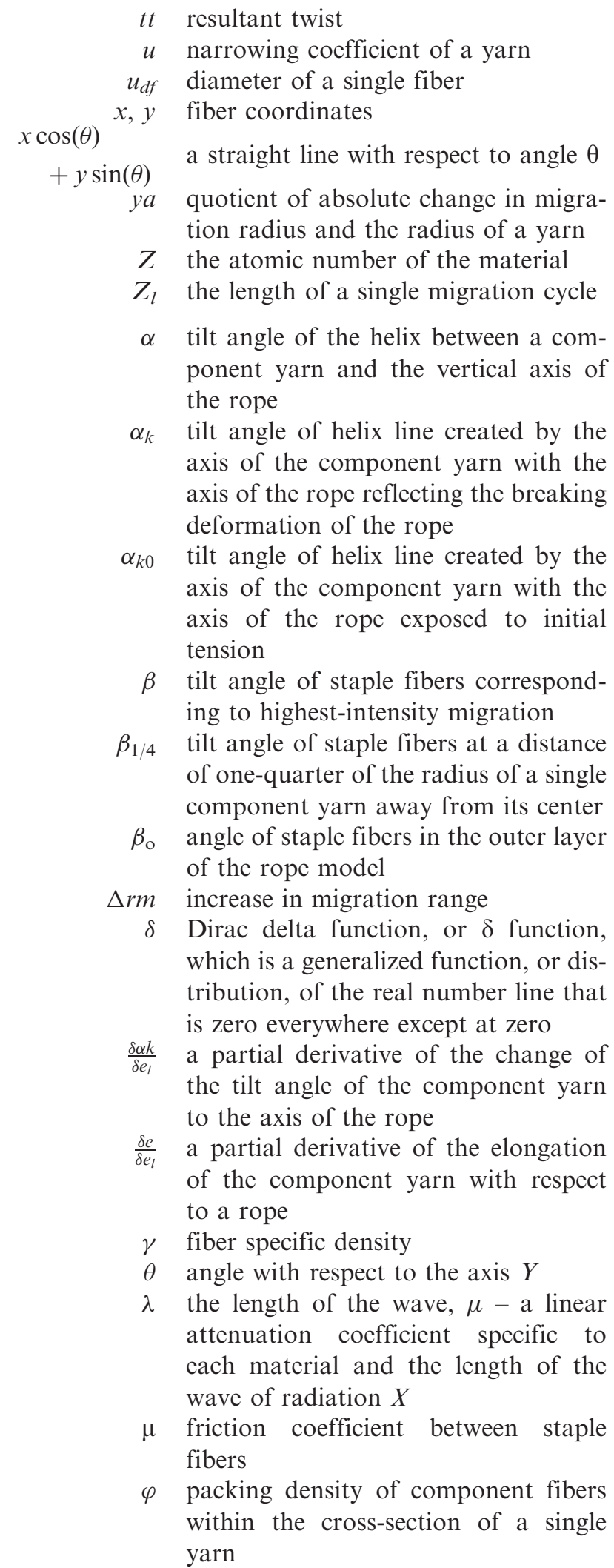

tt resultant twist

$u$ narrowing coefficient of a yarn

$u_{d f}$ diameter of a single fiber

a straight line with respect to angle $\theta$ quotient of absolute change in migration radius and the radius of a yarn

$Z$ the atomic number of the material

$\alpha$ tilt angle of the helix between a component yarn and the vertical axis of axis of the component yarn with the axis of the rope reflecting the breaking tilt angle of helix line created by the axis of the component yarn with the of the rope exposed to initial tilt angle of staple fibers corresponding to highest-intensity migration of one-quarter of the radius of a single component yarn away from its center of the rope model

$\mathrm{rm}$ increase in migration range

Dirac delta function, or $\delta$ function, which is a generalized function, or distribution, of the real number line that is zero everywhere except at zero the tilt angle of the component yarn to the axis of the rope of the component yarn with respect o a rope

$\gamma \quad$ fiber specific density

angle with respect to th attenuation coefficient specific to each material and the length of the wave of radiation $X$ fibers yarn 